\title{
Formação em Psicologia: Estágios e Avaliação Psicológica
}

\author{
Angela de Fátima Soligo ${ }^{1}$ \\ ${ }^{1}$ Associação Brasileira de Ensino de Psicologia, SP, Brasil \\ Irani Tomiatto de Oliveira ${ }^{1}$ \\ ${ }^{1}$ Associação Brasileira de Ensino de Psicologia, SP, Brasil
}

\author{
Monalisa Muniz ${ }^{2}$ \\ ${ }^{2}$ Universidade Federal de São Carlos, SP, Brasil. \\ Daniela Sacramento Zanini ${ }^{3}$ \\ ${ }^{3}$ Pontifícia Universidade Católica de Goiás, GO, Brasil.
}

Resumo: Este artigo discute a formação em Psicologia no contexto da pandemia do Covid-19. Expõe os princípios e compromissos que norteiam o processo de formação, tomando como referência as Diretrizes Curriculares Nacionais e os valores que garantem uma prática profissional guiada pela ética, pela competência técnica e pela busca de uma sociedade democrática e justa. A partir de aporte histórico sobre o desenvolvimento da área e da formação em Psicologia e da análise das normativas legais e orientações emitidas pelos órgãos reguladores nesse período de exceção, reflete sobre duas das atividades que estão entre as mais desafiadoras quando se fala em atividades remotas emergenciais: os estágios obrigatórios e o ensino da avaliação psicológica. Os estágios têm importância ímpar no processo de formação, uma vez que permitem a consolidação de conhecimentos, habilidades e competências a partir de experiências em situações reais de trabalho. A avaliação psicológica, por sua vez, atividade privativa do psicólogo, exige, para sua aprendizagem, contato direto com instrumentos e contextos de avaliação, e prática em situações reais. Consideradas a relevância e as exigências desses dois tipos de atividades para a formação do psicólogo, e as demandas por flexibilidade e busca de alternativas para esse período de isolamento social, se analisa os limites e possibilidades das atividades remotas, confrontandoas com as exigências necessárias para uma formação de qualidade.

Palavras-Chave: Formação em Psicologia, Estágios, Avaliação Psicológica, Ensino Remoto Emergencial, Pandemia de Covid-19.

\section{Psychology Training: Internships and Psychological Assessment}

\begin{abstract}
This article discusses Psychology training in the context of the COVID-19 pandemic. It describes the principles and commitments that guide the training process, taking as reference the Brazilian Curriculum Guidelines and the values that ensure professional practice guided by ethics, technical competence and the pursuit for a democratic and fair society. Based on a historical contribution on the development of the field and of Psychology training and on the analysis of legal norms and guidelines issued by the regulatory agencies in this period of exception, we discuss two of the most challenging activities when it comes to remote activities emergency: compulsory internships and psychological assessment teaching. Internships are unparalleled in the training process, as they allow to consolidate knowledge, skills and competences based on experiences in real work situations. In order to learn how to perform psychological assessments, a private activity of the psychologist, direct contact with assessment instruments, contexts, and practice in real situations are required. Given the relevance and requirements of these two types of activities for psychologist training, and the demands for flexibility and alternatives for this period of social isolation, we analyze the limits and possibilities of remote activities, confronting them with the requirements necessary for quality training.
\end{abstract}

Keywords: Psychology training, Internships, Psychological Assessment, Emergency Remote Teaching, Covid-19 pandemic. 


\title{
Formación en Psicología: Pasantías y Evaluación Psicológica
}

\begin{abstract}
Resumen: Este artículo analiza la formación en psicología en el contexto de la pandemia de Covid-19. Presenta los principios y compromisos que orientan el proceso de formación, tomando como referencia los Lineamientos Curriculares Nacionales y los valores que garantizan un ejercicio profesional guiado por la ética, la competencia técnica y la búsqueda de una sociedad democrática y justa. Con base en un aporte histórico sobre el desarrollo del área y en la formación en psicología y en el análisis de las normas y lineamientos legales emitidos por los organismos reguladores en este período de excepción, se reflexiona sobre dos de las actividades que se encuentran entre las más desafiantes cuando se habla de actividades remotas de emergencia: las pasantías obligatorias y la enseñanza de la evaluación psicológica. Las prácticas tienen una importancia singular en el proceso de formación, ya que permiten la consolidación de conocimientos, habilidades y competencias a partir de experiencias en situaciones laborales reales. La evaluación psicológica, actividad privada del psicólogo, requiere, para su aprendizaje, el contacto directo con los instrumentos y contextos de evaluación y la práctica en situaciones reales. Considerando la relevancia y exigencias de los dos tipos de actividades para la formación del psicólogo y las demandas de flexibilidad y búsqueda de alternativas para este período de aislamiento social, se analizan los límites y posibilidades de las actividades remotas al compararlos con los requisitos necesarios para la formación de calidad.
\end{abstract}

Palabras clave: Formación en Psicología, Pasantías, Evaluación Psicológica, Enseñanza Remota de Emergencia, Pandemia de Covid-19.

\section{Introdução}

A história de toda ciência é marcada pelas características, demandas e dilemas de seu espaço tempo. A Psicologia, como ciência, profissão e formação, carrega em sua história essas marcas. Sua constituição como ciência moderna na Europa do século XIX insere-se em um contexto de profundas transformações sociais e econômicas, com o desenvolvimento do capitalismo moderno e a tarefa de construção de um novo homem - ruptura com os modos familiares de produção, separação entre o mundo doméstico e o mundo do trabalho e instalação do individualismo e do ideário de progresso meritocrático como visão de mundo hegemônica (Castro \& Costa, 2018). A Psicologia moderna nascia marcada pelo projeto de sociedade que se instalava e, a partir dos princípios metodológicos das ciências naturais - neutralidade, objetividade, verificabilidade e quantitativismo -, elaborava os saberes que definiriam padrões de normalidade, de desenvolvimento e aprendizagem desejáveis e esperados desse novo homem (Patto, 1984; Ghiraldello, 2005).

Em seu desenvolvimento, a Psicologia foi ganhando novos contornos teórico-metodológicos. A psicanálise de Freud, com a psicopatologia da vida cotidiana, rompe com a ideia de uma rígida separação entre o normal e o anormal, propondo que o inconsciente opera em todos os sujeitos e as neuroses são componentes da personalidade dita normal (Freud, 1987). Piaget, contrariando os princípios da psicometria que apregoavam uma inteligência inata, imutável e desconectada da realidade concreta, veio propor uma concepção de inteligência dinâmica, fruto de um processo recíproco de interação com a realidade das coisas e das pessoas (Piaget, 1974).

A Psicologia social europeia, rompendo com uma visão de sociedade centrada nos grupos sociais e suas condutas, perspectiva dominante na tradição comportamental estadunidense, propõe pensar o homem como sujeito histórico, constituído no conjunto das relações sociais e culturais, determinadas pelas condições estruturais de cada sociedade (Moscovici, 2003). Não se pode pensar, portanto, uma Psicologia estanque, unitária, mas sim uma ciência e profissão que se constitui diariamente e trafega na trama das relações sociopolíticas em que se insere.

Com a marca da modernidade, a Psicologia ingressou no Brasil pelas portas da Educação, da Medicina e da Filosofia, a partir de meados do século XIX, como 
conteúdo de formação (Antunes, 2012). Desde sua inserção no campo da Educação, compôs os currículos para formação de jovens no ensino médio - experiência que se inicia no Colégio Pedro II, no Rio de Janeiro, em 1850 - e, a partir de 1890, os cursos de magistério - formação de professores, na Pedagogia e licenciaturas -, condição que ocupa até nossos dias. Compõe desde então até hoje a formação das áreas de saúde e das ciências humanas e sociais (Soligo, 2010; Vilela, 2012).

Se os primórdios da Psicologia no Brasil foram marcados por uma perspectiva normalizante e normatizante, calcada no modelo positivista de ciência e servido à rotulação da diferença e ajustamento dos "diferentes" em distintos campos, sua história, formada nas contradições sociais que caracterizam as sociedades modernas, vai mostrar os muitos movimentos críticos, reflexivos e autoavaliativos que nos levaram à produção de um projeto de ciência e profissão comprometido com as transformações sociais e com nossas gentes, na perspectiva de construção coletiva de bem estar social e busca de condições igualitárias, e ao mesmo tempo diversas, de existência (Bock, 2003). A diversidade de aportes teórico-metodológicos, de fundamentos político-filosóficos, de campos e espaços de atuação da psicóloga e do psicólogo constitui característica dessa Psicologia em movimento, assim como a atenção e compromisso com questões e temáticas antes negligenciadas, como as temáticas raciais e de gênero, das relações de poder, das políticas públicas, entre outras. A formação em Psicologia acompanha e traduz em suas diretrizes curriculares esse movimento (Kahhale, 2018).

A profissão de psicólogo foi regulamentada em 27 de agosto de 1962, por meio da Lei 4.119, que estabelecia o currículo mínimo para formação em Psicologia. De acordo com o currículo mínimo, a formação em Psicologia previa três terminalidades: bacharelado, que formava o pesquisador, licenciatura, que formava o professor de Psicologia, e formação de psicólogos, que habilitava ao exercício profissional (Cury \& Ferreira Neto, 2014). O currículo mínimo era organizado por disciplinas, que envolviam conhecimentos e áreas específicas da Psicologia, como Psicologia do Desenvolvimento, Psicologia da Aprendizagem, Psicometria, Teorias Psicoterápicas, Psicologia Industrial, Psicologia Escolar e problemas de aprendizagem, Psicologia Clínica, entre outras. Previa também a oferta de conteúdos relativos a áreas afins, como Filosofia, Sociologia, Fisiologia e Genética.
Três áreas fundamentais compunham a experiência pré-profissional (de estágio): Clínica, Escolar e Industrial. Na prática, no entanto, era a área clínica a que recebia a maior carga horária, tanto de disciplinas quanto de estágios (Boarini, 2007; Prates, Feitosa, Monteiro, \& Branco, 2019). Essa configuração vinha marcada por uma concepção do trabalho em psicologia que entendia o psicólogo como profissional liberal, sedimentada a partir do modelo médico de atuação individualizado e remediativo -, o que justificava a priorização da formação clínica, ao mesmo tempo em que alimentava e era alimentada pela representação social do psicólogo como o "profissional do divã".

O regime ditatorial militar que governou o país por mais de 20 anos certamente impunha limites à atuação de psicólogas e psicólogos dentro dos parâmetros da classificação e ajustamento. Se o contexto de ameaças e medo impôs obstáculos ao desenvolvimento da Psicologia crítica, ele não impediu os processos reflexivos e críticos que cresciam juntamente com o descontentamento em relação ao regime de opressão. Muitos foram os questionamentos e rupturas que se operaram ao longo dessas décadas, na perspectiva da crítica ao modelo médico individualizante, na desmistificação da ideia de uma ciência psicológica neutra e supostamente objetiva, e da problematização do papel da Psicologia na sociedade, nas instituições e na busca articulada de transformações sociais (Gil, 1985).

Nessa trajetória, relevantes transformações podem ser observadas: a psicometria, voltada inicialmente à aprendizagem e aplicação de testes (sem dúvida constituintes do ato de avaliar), foi sendo ampliada e ganhou contornos analíticos importantes; contemporaneamente falamos em avaliação psicológica, que representa nível avançado de amplitude e profundidade (Cortez, 2019). A Psicologia Industrial de nossos primórdios passou, ao longo dos anos 70 em diante, a ser concebida como Psicologia Organizacional e, contemporaneamente, como Psicologia do Trabalho, o que indica não apenas ampliação do olhar e das possibilidades de prática, mas principalmente o compromisso com o trabalhador e trabalhadora, onde quer que atuem (Campos, Duarte, Cezar, \& Pereira, 2011). A Psicologia Escolar, de uma configuração inicial marcada pela rotulação da não aprendizagem, pelo reforçamento da queixa escolar, pela solução individual de problemas e pelo exercício da clínica na 
escola, a partir dos anos 80 assume a compreensão de que aprendizagem, conduta e relações que ocorrem no espaço escolar não podem ser entendidas de forma apartada da realidade da escola, dos sistemas educativos e do funcionamento da sociedade. Nessa perspectiva, constitui-se como Psicologia Escolar crítica e empreende pesquisas e estratégias de atuação na perspectiva inclusiva da garantia do acesso aos saberes construídos pela humanidade e da atenção ao trabalho docente, às vozes dos estudantes e às culturas escolares (Campos, Souza, \& Facci, 2018). A prática clínica amplia seus horizontes em relação à configuração elitista dos seus primórdios, amplia seus espaços e modos ao se inserir nas políticas públicas de Saúde e Assistência Social, e hoje busca os espaços comunitários, em perspectiva emancipadora (Cintra \& Bernardo, 2017). Vimos desenvolver-se no país a Psicologia Social crítica, a Psicologia Comunitária, Jurídico-Forense-Penal, do Esporte e das Emergências e Desastres, trilhando os caminhos da formação humana, compromisso social e emancipação cidadã (Rechtman, 2015).

Importantes Resoluções do Conselho Federal de Psicologia (CFP) evidenciam essas transformações: a Resolução CFP 001/99, que proíbe a psicólogos considerar homossexualidade como doença e oferecer cura, bem como divulgar conteúdos preconceituosos; a Resolução CFP 018/2002, que estabelece o compromisso profissional com a não-difusão e orientação do trabalho por práticas racistas; e a Resolução CFP 01/2018, que orienta os profissionais a não patologizar as identidades trans. Certamente, esse não foi e não é um caminho em linha reta; ao contrário, é um caminho histórico, marcado por contradições, mudanças e permanências. Não há dúvidas, porém, das relevantes mudanças que se expressam em nossa história.

Quanto aos processos de formação e sua imbricação com a dinâmica social, o final dos anos 80 representou uma importante ruptura com a ditadura militar que governou o país por mais de 20 anos e retomada do processo democrático, com a promulgação da Constituição de 1988 (Chauí \& Nogueira, 2007). Do mesmo modo, com a aprovação da Lei de Diretrizes e Bases da Educação Nacional, em 1996, que estabeleceu a inclusão e universalização da educação básica como princípios, importantes mudanças se anunciavam para a formação superior no Brasil (Brzezinski, 2010).

A partir de 1999, partindo de um modelo de ensino articulado com a perspectiva de competências e habilidades, difundido em contexto europeu por vários autores e assumido como parâmetro em diversos países, o Ministério da Educação (MEC) estabeleceu o padrão de formação superior com base em competências para todos as áreas de formação, e determinou um prazo para transposição ao novo modelo, na forma de Diretrizes Curriculares, não mais baseadas em disciplinas e áreas estanques (Pereira, 2014). As Diretrizes Curriculares Nacionais (DCNs) para os Cursos de Graduação em Psicologia foram aprovadas em 2004, por meio da Resolução $\mathrm{n}^{\circ} 08$ do MEC/Conselho Nacional de Educação (CNE)/CES (Conselho Nacional de Educação, 2004). Sua elaboração foi fruto de intensos debates e negociações, na medida em que havia dois projetos de formação em disputa: a formação generalista ou a formação especializada em áreas. Sua configuração expressa essas diferenças e os caminhos de conciliação encontrados: a formação generalista, com terminalidade em ênfases curriculares eletivas (Seixas, 2014).

As DCNs de 2004 assumem o compromisso com os Direitos Humanos, com as políticas públicas de saúde e com a formação generalista. Caracterizam-se pelo estabelecimento de competências esperadas para a constituição da identidade profissional, pela definição dos processos que descrevem o trabalho das/dos psicólogas/os, pela transversalização da pesquisa, e pela organização dos estágios em básicos e de ênfase. As ênfases, nessa perspectiva, constituem aprofundamentos que refletem as produções acadêmicas das instituições de ensino e as particularidades regionais. É notável o avanço que essas DCNs representam, ao assumirem explicitamente postura de compromisso social e ao contemplarem uma formação que supera a configuração disciplinar e possibilita a inserção de novos saberes e práticas na formação em Psicologia. Em 2011, as DCNs foram reformuladas, por meio da Resolução ${ }^{\circ} 05 \mathrm{MEC} / \mathrm{CNE} / \mathrm{CES}$ (Conselho Nacional de Educação, 2011), com o objetivo de regulamentar o artigo 13, referente à licenciatura - formação de professores de Psicologia. No mais, todo o texto e princípios de 2004 foram preservados.

Não podemos deixar de mencionar o momento político que vivíamos nos anos 90 e nos primeiros quinze anos da década de 2000, com a retomada do processo democrático que possibilitou a abertura a modos emancipados de ensino e produção de conhecimentos para o estudo de temáticas antes silenciadas, bem como impulsionou políticas públicas e de 
garantia de direitos e políticas inclusivas e afirmativas, abrindo espaço para novas experiências de atuação na sociedade (Urt, 2017). Esse clima de otimismo quanto ao futuro do país expressa-se no texto das diretrizes de 2004 e 2011, como esperança de uma formação que produziria saberes e profissionais comprometidos com a transformação social.

Não podemos dizer a mesma coisa das experiências e do clima que passamos a viver a partir do golpe de 2016, com as políticas de flexibilização do trabalho, aprovação do teto de gastos em educação e saúde, e principalmente com a eleição em 2018 de um governo federal de ultradireita, que vem se notabilizando pela retirada de direitos e aprofundamento das desigualdades sociais (Júnior \& Fargoni, 2020). No âmbito do ensino superior, os últimos quatro anos têm representado cortes de investimentos nas universidades públicas brasileiras, retirada de verbas para a pesquisa acadêmica e redução drástica nas políticas de bolsas e financiamento do ensino superior. O Projeto Future-se, apresentado como grande proposta para o ensino superior federal, trilha o caminho da privatização e da transformação da carreira e trabalho docente em empreendimentos individuais e solitários na busca de financiamento para seus projetos (Grupo de Pesquisa Trabalho, Precarização e Resistências \& Centro de Estudos e Pesquisas em Humanidades da Universidade Federal da Bahia, 2019).

Nas instituições privadas, têm sido recorrentes as demissões em massa de docentes, bem como a intensificação do trabalho para aquelas e aqueles que nelas se inserem. É no bojo dessas mudanças, no contexto da intensificação do modelo neoliberal, que a Educação à Distância (EaD) ganha força e incentivo governamental, na tentativa de, atendendo aos anseios das grandes empresas que vendem pacotes de ensino à distância, transpor de forma permanente o ensino superior para o modelo EaD (Sousa, 2019). As políticas de $\mathrm{EaD}$, que já se inserem em muitas áreas de formação, têm batido às portas dos cursos da área de Saúde, inclusive a Psicologia, que vêm tentando resistir a esse modelo que degrada a qualidade da formação, por meio de sua articulação junto ao Conselho Nacional de Saúde (Conselho Federal de Psicologia \& Associação Brasileira de Ensino de Psicologia, 2018).
Esses movimentos de resistência incluíram, no ano de 2017, a organização de um processo de revisão das DCNs para os Cursos de Graduação em Psicologia, organizado pela Associação Brasileira de Ensino de Psicologia (ABEP), CFP e Federação Nacional dos Psicólogos (FENAPSI). Essa ação vinha articulada com as demais áreas de Saúde, na tentativa de promover avanços nas perspectivas de formação e evidenciar a presencialidade como princípio irredutível da formação. Denominado "Ano da Formação em Psicologia", o processo de revisão das diretrizes foi organizado em perspectiva democrática e participativa, com a realização de 118 reuniões preparatórias distribuídas por todo o país - envolvendo profissionais, docentes e estudantes de Psicologia -, 5 Encontros Regionais e o Encontro Nacional, que ocorreu em 5 de maio de 2018 (Conselho Federal de Psicologia \& Associação Brasileira de Ensino de Psicologia, 2018).

Para orientar o processo, foi elaborado pela ABEP um roteiro de discussão, que problematizava distintos elementos constituintes das diretrizes, como os princípios da formação, o perfil do estudante, as metodologias de ensino aprendizagem, a pesquisa, extensão, a licenciatura, entre outros. Cada etapa resultou em propostas de conteúdo para as diretrizes que foram discutidas e aprovadas no Encontro Nacional. Essas foram então organizadas na forma de minuta, disponibilizada para consulta pública para toda a comunidade acadêmica e profissional. Posteriormente, a minuta foi objeto de análise e contribuições das entidades do Fórum Nacional das Entidades da Psicologia Brasileira (FENPB), que propôs alterações na direção de aperfeiçoar o texto. Feitas as adequações, a minuta - que foi aprovada previamente no Conselho Nacional de Saúde - foi enviada ao Conselho Nacional de Educação. A Câmara de Ensino Superior do Conselho Nacional de Educação (CNE) acolheu a minuta e designou comissão para emitir parecer, ao mesmo tempo em que as entidades da Psicologia elegeram três representantes ${ }^{1}$ que fariam a mediação com a equipe parecerista do CNE. Desse diálogo, a minuta foi aperfeiçoada, porém garantindo os princípios e pontos que considerávamos inegociáveis.

Em audiência pública no CNE, o CFP, ABEP, Conselhos Regionais de Psicologia (CRPs) e demais

\footnotetext{
${ }^{1}$ Representaram a Psicologia a psicóloga Dra. Irani Tomiatto de Oliveira, pela ABEP, a psicóloga Dra. Raquel Souza Lobo Guzzo, pela Associação Nacional de Pós-graduação e Pesquisa em Psicologia (ANPEPP), e o psicólogo Dr. Antonio Virgílio Bastos, pela Associação Brasileira de Psicologia Organizacional e do Trabalho (SBPOT).
} 
entidades da Psicologia puderam, organizadamente, expressar seu apoio às novas diretrizes. As novas DNCs para os Cursos de Graduação em Psicologia foram aprovadas no CNE, por meio do Parecer CNE/CES 1071 de 2019, e aguardam homologação pelo MEC. Seu texto reafirma o compromisso com os Direitos Humanos e determina os eixos das políticas públicas: inclusão, atenção às diferenças e desigualdades, bem como a formação generalista e presencial. Os processos estruturais de produção das desigualdades são assumidos como fundamentos para a compreensão do sofrimento psíquico e psicossocial. Estes criam a necessidade de construção de novos saberes em Psicologia, referenciados na produção latino-americana. Mantém-se a estruturação em núcleo comum e ênfases, pautada em competências e processos de trabalho que devem ser desenvolvidas por meio de conhecimentos disciplinares e práticas, e transversalizados pela pesquisa científica e pelos princípios éticos da profissão.

Podemos dizer que, se em 2004 e 2011 a configuração das diretrizes vinha no caminho de um otimismo quanto aos rumos do país e às possibilidades que se abriam na direção das políticas de bem estar e campos de trabalho para a Psicologia, em 2019 essas diretrizes trazem a marca da resistência e da defesa de princípios de cidadania e direitos duramente conquistados e agora ameaçados.

Quando afinal esperávamos ver nossas diretrizes homologadas pelo MEC, o país e o mundo foram surpreendidos por uma pandemia de proporções globais, causada pela Covid-19, para a qual ainda não se tem vacina ou medicação de eficácia comprovada. A pandemia impôs necessárias medidas de afastamento social e quarentena, bem como normativas oficiais relativas ao funcionamento da educação em todos os níveis de ensino. Entre elas, o cancelamento das atividades presenciais em todos os níveis educacionais e transposição para meios remotos, mediados por tecnologias da informação e comunicação (TIC).

As Portarias do MEC 343, 345, 349 e 473/2020 autorizaram a transposição das atividades presenciais de ensino superior para meios remotos, ao mesmo tempo vetando a realização de práticas e estágios por esses meios. Coordenações de curso, docentes e estudantes passaram a demandar orientações sobre as possibilidades e limites para realização das atividades acadêmicas em Psicologia, o que gerou a publicação de duas notas orientadoras por parte da ABEP, CFP e FENAPSI, em março de 2020, e do CFP e ABEP, em junho de 2020, orientando sobre $o$ atendimento às Portarias do MEC e vetos estabelecidos, bem como expressando preocupação quanto aos princípios éticos e técnicos da formação e quanto à acessibilidade dos estudantes aos meios digitais e ferramentas de internet.

No final de junho de 2020 o MEC editou a Portaria $544 / 2020$, que abriu a possibilidade de transposição para meios remotos das práticas e estágios. No bojo da precariedade que se delineava, as investidas contra o ensino superior por meio de pacotes de $\mathrm{EaD}$ trouxeram insegurança ao corpo docente e coordenações, materializadas em redução de salários e demissões em massa no ensino privado e, nas instituições públicas, em mais cortes e redução de investimentos. Para as e os estudantes, representaram preocupações com relação à continuidade e qualidade de seus cursos. Diante dessa nova realidade, fez-se necessário promover ampla discussão com a comunidade acadêmica e entidades científicas a respeito das possibilidades e limites éticos da realização das práticas de estágio remoto em Psicologia.

Amplo processo de discussão foi desencadeado por proposta do CFP e ABEP e organização dos CRPs e Núcleos ABEP, envolvendo os coordenadoras/es de curso, docentes e orientadoras/es de estágio, e estudantes em todos os estados brasileiros. Esse rico processo de debates, apontamentos de dificuldades e expectativas, proposições e exposições de possibilidades, reflexões de natureza ética e inclusiva, foi descrito em minuciosos relatórios estaduais, que deram origem e fundamento para a organização do documento Práticas e Estágios Remotos no contexto da pandemia da Covid 19 - Recomendações, elaborado pelo CFP e ABEP e disponibilizado para toda a comunidade acadêmica, CRPs e Núcleos ABEP (Conselho Federal de Psicologia \& Associação Brasileira de Ensino de Psicologia, 2020).

Essa trajetória revela nosso compromisso com princípios caros à vida cidadã: os direitos humanos, 0 respeito à diferença e enfrentamento das desigualdades, e a defesa das políticas públicas promotoras de bem estar. Na formação, evidencia ainda nossa defesa da qualidade ética e técnica, da presencialidade essencial à construção da identidade da e do futuro(a) profissional. Entre entusiasmo e resistência vamos tecendo coletivamente os caminhos da formação em Psicologia.

Neste sentido damos destaque, no presente artigo, a duas das atividades que estão entre as mais 
desafiadoras quando se fala em atividades remotas emergenciais: os estágios obrigatórios e o ensino da avaliação psicológica. Ambas as atividades estão intimamente relacionadas com o exercício profissional e demandam contato físico como forma de treino de competências necessárias.

\section{Estágios Em Psicologia}

A principal referência legal sobre estágios no país é a Lei $\mathrm{N}^{\circ} 11.788$, publicada em 25 de setembro de 2008 e comumente denominada Lei de Estágio. Em seu artigo $1^{\circ}$. encontra-se a seguinte definição:

Estágio é ato educativo escolar supervisionado, desenvolvido no ambiente de trabalho, que visa à preparação para o trabalho produtivo de educandos que estejam frequentando o ensino regular em instituições de educação superior, de educação profissional, de ensino médio, da educação especial e dos anos finais do ensino fundamental, na modalidade profissional da educação de jovens e adultos (Brasil, 2008).

Alguns termos dessa definição merecem atenção especial para a compreensão dessa atividade: ela só pode ser realizada por estudante regularmente matriculado em ensino regular, trata-se de ato educativo supervisionado e deve ser desenvolvida em ambiente de trabalho. Depreende-se daí, portanto, que no âmbito da educação superior, o estágio é parte da formação profissional inicial; não é atividade profissional propriamente dita, embora introduza o estudante nessa atividade, mas trata-se de ato educativo, obrigatoriamente acompanhado de supervisão, e não se refere a atividades simuladas ou de treinamento com base em casos ou situações não-reais ou não-presentes (por exemplo, casos ou situações relatados pelo docente como exemplos, discussão de literatura, filmes, role playing, entre outros). É realizado em ambiente de trabalho.

A Lei de Estágio (Lei № 11.788/2008) estabelece que existem estágios obrigatórios, que compõem o projeto pedagógico e a carga horária dos cursos, e não obrigatórios, realizados como atividade opcional. Entre outros aspectos relevantes estabelece ainda a obrigatoriedade da celebração de Termo de Compromisso de Estágio entre as três partes envolvidas - instituição de ensino, concedente do estágio e estagiário -, da orientação de estágio, realizada por professor da instituição de ensino, e da supervisão, realizada por profissional da parte concedente. Define ainda as obrigações de cada uma dessas partes envolvidas no estágio. Trataremos, neste texto, dos estágios obrigatórios, que integram necessariamente o processo de formação.

Nos cursos de graduação em Psicologia, que são aqui nosso objeto de atenção, a presença dos estágios é obrigatória desde sua criação. O Parecer do Conselho Federal de Educação № 403/62, publicado logo após a regulamentação da profissão, estabeleceu o currículo mínimo para os cursos, do qual fazia parte, obrigatoriamente, um período de treinamento prático sob a forma de estágio supervisionado (Jacó-Vilela, 1999).

No decorrer dos anos seguintes, o CFP, criado para regulamentar e orientar o exercício profissional do psicólogo, reconhecendo sua responsabilidade sobre a qualidade da formação - como garantia de uma atividade profissional de qualidade - e sobre os serviços psicológicos oferecidos à população no decorrer dos estágios criou diversos documentos, orientações e resoluções sobre essa etapa preparatória e supervisionada do exercício profissional. Além disso, outras resoluções e normativas do CFP, relacionadas ao exercício profissional propriamente dito, também se aplicam a práticas desenvolvidas nos estágios. Apenas para citar alguns exemplos, temos o Código de Ética do Profissional Psicólogo (CEPP) (Conselho Federal de Psicologia, 2005), o Registro Documental (Conselho Federal de Psicologia, 2009), o Manual de Produção de Documentos (Conselho Federal de Psicologia P, 2003), a Consolidação das Resoluções do Conselho Federal de Psicologia (Conselho Federal de Psicologia, 2007) e a Carta de Serviços sobre Estágios e Serviços-Escola (Conselho Federal de Psicologia, 2013).

Neste momento, um Grupo de Trabalho está elaborando um novo documento, visando à atualização das orientações a respeito dos estágios.

\section{As DCNs para os cursos de graduação em Psicologia}

As DCNs publicadas pelo Ministério da Educação constituem-se no documento que normatiza e orienta a elaboração dos projetos pedagógicos dos cursos. As primeiras DCNs para os cursos de graduação em Psicologia (Conselho Nacional de Educacão, 2004) foram publicadas após 42 anos de vigência do currículo mínimo. Elas representam uma mudança na 
concepção dos cursos e trazem conceitos inovadores, alguns deles referentes aos estágios. Em artigos específicos, eles são definidos, assim como seus objetivos, e divididos em dois níveis, básico e específico:

Art. 20. Os estágios supervisionados são conjuntos de atividades de formação, programados e diretamente supervisionados por membros do corpo docente da instituição formadora, e procuram assegurar a consolidação e a articulação das competências estabelecidas.

Art. 21. Os estágios supervisionados visam assegurar o contato do formando com situações, contextos e instituições, permitindo que conhecimentos, habilidades e atitudes se concretizem em ações profissionais, sendo recomendável que as atividades do estágio supervisionado se distribuam ao longo do curso.

Art. 22. Os estágios supervisionados devem se estruturar em dois níveis - básico e específico cada um com sua carga horária própria.

$\$ 1^{\circ} \mathrm{O}$ estágio supervisionado básico incluirá o desenvolvimento de práticas integrativas das competências e habilidades previstas no núcleo comum.

$\S 2^{\circ}$ Cada estágio supervisionado específico incluirá o desenvolvimento de práticas integrativas das competências, habilidades e conhecimentos que definem cada ênfase proposta pelo projeto de curso (Conselho Nacional de Educação, 2004, p.6).

As DCNs de 2011 reproduzem exatamente esses artigos, uma vez que sua única diferença, em relação à resolução de 2004, reside no artigo 13, que trata da licenciatura. Importante observar que tanto os básicos quanto os específicos são estágios, portanto devem obedecer às exigências da Lei de Estágio (Brasil, 2008), tais como Termo de Compromisso entre as partes, orientação, supervisão e, especialmente, realização em ambiente de trabalho. Muita distorção tem sido feita em relação à concepção de estágio básico, transformando-o, por exemplo, em atividades simuladas, discussão de literatura e até em atividades teóricas. Essas atividades não atendem, de forma alguma, ao que está estabelecido na legislação.
Essa distorção parece ser fruto, algumas vezes, de uma compreensão equivocada sobre a concepção de estágio básico, e em outras parece ser resultado da interferência de questões econômicas - uma vez que os estágios, em geral, representam a parte mais onerosa da formação do psicólogo para as instituições de ensino, dada a necessidade de acompanhamento individualizado ou em pequenos grupos, com carga horária suficiente e por docentes qualificados. Assim, quando prevalece a visão mercadológica da educação, e o lucro financeiro é o objetivo principal, os estágios costumam ser a parte mais prejudicada, comprometendo gravemente a formação profissional.

Para evitar a compreensão equivocada sobre as características e condições desses estágios, que pode ser em parte induzida pelo adjetivo “básico", que por sua vez pode remeter a simples ou inicial, as novas DCNs para os cursos de Psicologia, aprovadas pelo Conselho Nacional de Educação (Conselho Nacional de Educação, 2019) e ainda não homologadas, substituíram esse termo por Estágios do Núcleo Comum. Em seu artigo 8, definem que o Núcleo Comum da formação deve desenvolver, no estudante, as competências que definem o perfil profissional do psicólogo. E reza o parágrafo $1^{\circ}$ desse artigo que o conjunto de competências básicas deve assegurar a possibilidade de prestação de serviços psicológicos à sociedade em diferentes domínios, atendendo as demandas sociais concretas em contextos de trabalho nos quais o psicólogo se insere (Conselho Nacional de Educação, 2019). Portanto, os Estágios do Núcleo Comum não são necessariamente simples ou iniciais, mas caminham da baixa para a alta complexidade, acompanhando o processo de formação e garantindo a consolidação e a integração das competências a serem desenvolvidas durante o processo de formação.

Nas DCNs aprovadas pelo Parecer CNE/CES № 1071/2019, as características e condições dos estágios obrigatórios são assim definidas:

Art. 14. O projeto de curso deve incluir os estágios obrigatórios supervisionados que garantam a articulação entre os diferentes componentes curriculares e a consolidação das competências que compõem o perfil do egresso.

$\S 1^{\circ}$ As atividades de estágio obrigatório supervisionado devem ser orientadas de acordo com as normativas legais e com os preceitos éticos da prática profissional. 
$\S 2^{\circ}$ Os estágios obrigatórios supervisionados devem assegurar o contato do estudante com diferentes situações e contextos de trabalho, e serem distribuídos ao longo do curso.

$\S 3^{\circ} \mathrm{A}$ atividade de estágio obrigatório supervisionado deve ter orientação presencial, conduzida por professores psicólogos, docentes da instituição formadora.

Art. 15. Os estágios obrigatórios supervisionados devem estruturar-se em dois níveis: estágios do núcleo comum e estágios das ênfases curriculares, acompanhando o processo de formação.

$\$ 1^{\circ}$ Os estágios do núcleo comum incluem o desenvolvimento e a integração das competências previstas no núcleo comum da formação e devem contemplar a diversidade do campo da Psicologia.

$\S 2^{\circ}$ Os estágios das ênfases curriculares visam ao desenvolvimento e à integração das competências ligadas aos diferentes processos de trabalho desenvolvidos nas ênfases curriculares do curso e ao perfil de cada instituição formadora (Conselho Nacional de Educação, 2019, p.12).

O processo de construção dessas DCNs foi amplo e democrático, fruto da participação e de discussões e reflexões que envolveram todos os atores da formação profissional, capilarizados por todo o país. Esse processo foi seguido de uma detalhada negociação com os membros da Comissão do CNE responsável pela sua apresentação ao Conselho de Educação Superior e de uma consulta pública, que teve expressiva participação da categoria. Assim, representa efetivamente a visão do psicólogo que queremos formar, e de qual consideramos ser a forma adequada de realizar esse desafio.

É consenso que os estágios que compõem o processo de formação representam nele uma parte sumamente importante. São eles que permitem a consolidação de competências, integrando saberes e práticas e oportunizando experiências reais e concretas que introduzem o estudante na atuação profissional do psicólogo, com o suporte e o amparo da orientação e supervisão de profissionais experientes. Além disso, os estágios permitem a oferta de serviços psicológicos à população, muitas vezes a uma população que dificilmente teria acesso a eles de outra forma. Decorre daí o cuidado com que esse tema precisa ser tratado, visando à garantia, por um lado, de uma formação de qualidade e, por outro, dos direitos a uma assistência adequada por parte dos usuários dos serviços que envolvem estágios. Também por esse motivo, as DCNs de 2019 ampliaram a presença dos estágios nos cursos, estabelecendo que no mínimo vinte por cento $(20 \%)$ da carga horária total do curso deve ser dedicado a eles, e estabelecendo ainda que eles se distribuam ao longo do curso, permitam ao estudante experiências em uma diversidade de situações e contextos e sejam orientados presencialmente por um membro do corpo docente da instituição formadora.

\section{Estágios em tempos de pandemia da Covid-19}

Poucos meses após a aprovação das novas DCN para os cursos de Psicologia pelo CNE (Conselho Nacional de Educação, 2019), ainda quando comemorávamos os resultados do profícuo processo de sua construção e aguardávamos sua homologação pelo Ministério da Educação para dar início a uma nova fase de sua implantação, o mundo se viu surpreendido pela pandemia da Covid-19, que alterou substancialmente a vida de todos e trouxe trágicas e tristes consequências. Entre tantas áreas atingidas pela pandemia, que nos tem colocado enormes desafios, está a da educação, em todos os níveis. Logo após o reconhecimento da pandemia pela Organização Mundial da Saúde, o MEC e o CNE iniciaram a publicação de uma série de documentos orientadores e reguladores para a educação nesse novo contexto de isolamento social, que vieram a público, especialmente, entre os meses de março e julho do presente ano (Ministério da Educação, 2020a, 2020b; Conselho Nacional de Educação, 2020)

Ao mesmo tempo, atendendo à enorme demanda por orientações na área da Psicologia, a ABEP, o CFP e outras entidades científicas e profissionais se manifestaram, na busca de parâmetros que orientassem a atuação profissional e a formação. Exemplos são a Nota Sobre Atividades Acadêmicas no Contexto da Pandemia (Associação Brasileira de Ensino de Psicologia, Conselho Federal de Psicologia, \& Federação Nacional dos Psicólogos, 2020), a Carta de Recomendações CFP/ABEP Sobre Estágios por Meio Remoto (Associação Brasileira de Ensino de Psicologia \& Conselho Federal de Psicologia, 2020) e os Seminários Regionais e Nacional realizados por essas entidades sobre estágios em Psicologia no contexto da pandemia. Desse 
seminário resultou um documento com recomendações sobre práticas e estágios remotos emergenciais nesse período, importante referência para coordenadores de curso, orientadores e supervisores de estágio e estudantes (Conselho Federal de Psicologia \& Associação Brasileira de Ensino de Psicologia, 2020).

A pandemia tem trazido sérias e profundas mudanças e restrições à vida em sociedade, tem adiado e/ou alterado projetos de vida, afetado gravemente a saúde e as condições econômicas de boa parte da população e, certamente, atingido a área da educação, devido ao isolamento social necessário como medida de cuidado e proteção à saúde. No que se refere à formação em Psicologia, entre os muitos desafios trazidos pelas condições impostas pela pandemia, certamente o mais complexo se refere à realização dos estágios. Eles têm o objetivo de colocar o estudante em contato com situações reais de trabalho, em uma diversidade de contextos, e desenvolver, entre outras, competências de relacionamento profissional para atuar em equipes multiprofissionais e para utilizar diferentes linguagens - visual, sonora, corporal. Devem permitir que o estudante, ao experimentar a práxis no mundo do trabalho, possa integrar conhecimentos, habilidades, competências e atitudes desenvolvidos ao longo do curso, sempre acompanhado de orientação qualificada.

A inserção dos estudantes na grande maioria dos contextos de trabalho, nesse período, não é possível assim como não é possível garantir uma formação de qualidade sem essas experiências. Portanto, mesmo reconhecendo as enormes dificuldades que sua postergação e, algumas vezes, a postergação da conclusão do curso podem trazer, não há como substituir as experiências reais dos estágios.

Disciplinas, a partir da autorização do MEC, têm sido ministradas por meio remoto, não sem consequências negativas, em especial no que se refere à falta de planejamento prévio, dada a situação de emergência, à sobrecarga e precarização do trabalho docente e à exclusão de boa parte dos estudantes, que não têm acesso aos recursos tecnológicos. No caso dos estágios, por mais que o momento exija flexibilidade e criatividade para se adaptar a uma situação tão inusitada, apenas uma parte muito reduzida das atividades poderia ser passível de realização por esse meio. As orientações das entidades que cuidam da formação e da atuação profissional - ABEP e CFP - a respeito dessas possibilidades encontram-se no documento Práticas e Estágios Remotos em Psicologia no Contexto da Pandemia da COVID-19: Recomendações (Conselho Federal de Psicologia \& Associação Brasileira de Ensino de Psicologia, 2020). O documento deixa claro que não é aceitável a realização de "adaptações" a qualquer custo que comprometem seriamente os direitos da população a serviços de qualidade e o futuro da Psicologia brasileira, a partir da precarização da formação de seus profissionais.

Os princípios que norteiam a formação e a atuação do psicólogo brasileiro e que orientaram a construção coletiva de nossas DCNs precisam ser sempre nossa referência principal: a ética, a competência técnica, a inclusão, o respeito a todas as diversidades, além do compromisso inalienável com a oferta de serviços psicológicos de qualidade à população, o que só é possível a partir de uma formação responsável.

\section{Avaliação Psicológica}

A história da avaliação psicológica (AP) se confunde com a própria história da Psicologia. De fato, o nascimento da ciência psicológica se deu em um laboratório por meio dos experimentos realizados por Wundt (1832-1920) para avaliação de estados psicológicos (Schultz \& Schultz, 2005). Desde então, a psicologia, em geral, e a AP, em específico, muito se desenvolveu. A AP se expandiu saindo do contexto laboratorial e clínico e adentrando diversos espaços e contextos (organizacional e do trabalho, trânsito, saúde etc.). Seus métodos, técnicas e procedimentos se desenvolveram significativamente e levaram ao reconhecimento de que se tratava de uma especialidade da Psicologia que demandava estudos aprofundados e formação continuada (após a graduação em Psicologia). Atualmente a AP é um campo de atuação profissional, reconhecido como especialidade pelo CFP no Brasil (Conselho Federal de Psicologia, 2019), que se insere em diferentes contextos.

Mais recentemente, a AP se expandiu, para além dos diferentes contextos, da modalidade presencial (lápis e papel) para a modalidade online ou remota (Primi, 2018). Contudo, essa expansão deve ser avaliada com cautela pois traz impactos significativos para a sociedade e os indivíduos. Um exemplo disso foi o uso dado a AP remota nas eleições americanas (Primi, 2018). De acordo com o que foi divulgado na imprensa científica e midiática, uma empresa observou o comportamento das pessoas nas redes sociais e por meio de associação com traços de personalidade 
conseguiu identificar e agrupar alguns perfis psicológicos. Com base nesses perfis desenvolveu uma propaganda eleitoral específica. Esta estratégia de marketing demonstrou-se extremamente eficaz pois conseguiu "comunicar-se" com as crenças, medos e desejos da população de forma mais individualizada, o que aumentava a chance de adesão ou assimilação do conteúdo divulgado (Matz, Kosinski, Nave, \& Stillwell, 2017). Nesse sentido, essa expansão e possibilidade de usos da AP merecem observações e cuidados éticos na prática profissional.

O paralelo e a intersecção da história da Psicologia com a AP é uma construção permanente, pois a AP é inerente à prática do psicólogo (Nunes et al, 2012). Para que se possa realizar uma intervenção psicológica, é necessário que previamente a psicóloga tenha minimamente analisado/avaliado a situação, o contexto e os envolvidos para que efetive uma prática ética e coerente com a demanda. Mesmo que inicialmente não se faça uma AP estruturada, na qual ocorre um processo mais elaborado de coleta e compreensão das informações, a análise/ avaliação mínima para alguns casos nos quais não se tenha condições inicialmente de se realizar uma AP mais estruturada também dependerá de competências bem desenvolvidas da profissional em AP, como por exemplo as técnicas de observação e entrevista, fundamentais no contato inicial.

Nas próprias DCNs de 2011 para os cursos de Psicologia (Conselho Nacional de Educação, 2011), e a de 2019, que aguarda a homologação do Ministério da Educação mas já foi aprovada pelo CNE (Conselho Nacional de Educação, 2019), se constata objetivos, habilidades e competências específicas da AP ou o uso desse processo antecedendo outros conhecimentos e práticas. Como exemplo, nas DCNs de 2011, no Art. $4^{\circ}$ sobre competências e habilidades gerais, o inciso 2 explicita: "Tomada de decisões: o trabalho dos profissionais deve estar fundamentado na capacidade de avaliar, sistematizar e decidir as condutas mais adequadas, baseadas em evidências científicas" (Conselho Nacional de Educação, 2011). Nas DCNs de 2019, no Art. 8 sobre competências básicas a serem desenvolvidas, no parágrafo $5^{\circ}$ das competências profissionais, embasado na Declaração Internacional de Competências Fundamentais na Psicologia Profissional (International Association of Applied Psychology \& International Union of Psychological Science, 2016), o inciso 7 diz respeito especificamente à AP pontuando: a) identificar a necessidade de avaliações em indivíduos, grupos, famílias, comunidades, organizações ou sociedades; b) utilizar os diversos métodos e estratégias de avaliação em Psicologia: entrevistas, observação, testes psicológicos, entre outros; c) selecionar, planejar e desenvolver avaliações utilizando métodos apropriados aos objetivos e aos propósitos das atividades; d) integrar métodos, análises, sínteses e interpretação dos dados coletados (Conselho Nacional de Educação, 2019).

E o inciso 8, sobre as bases para a realização de intervenções psicológicas e psicossociais, traz como primeiro fundamento "a) planejar, integrando dados de avaliação, intervenções psicológicas com indivíduos, grupos, comunidades, organizações e sociedade" (Conselho Nacional de Educação, 2019).

Essa conexão entre o fazer psicológico e a AP torna essa área da psicologia ainda mais proeminente quando se discute o ensino e a prática da psicologia em tempos da pandemia. Como a AP pode ser estendida a diferentes contextos e sua realização está muito ligada à atividade da prática profissional do psicólogo ela demanda o desenvolvimento de habilidades e competências específicas e que necessitam ser trabalhadas na graduação de forma prática. Porém, o estágio e, em certa medida, as próprias disciplinas relativas ao ensino de AP, apesar de serem parte da formação básica do futuro psicólogo, são o primeiro momento que o aluno irá desenvolver uma prática psicológica na qual irá envolver a sua relação com a comunidade, ou seja, atuar diretamente com pessoas para as quais oferecerá o serviço psicológico. Esta atuação, por envolver intrinsecamente uma prática profissional, deve estar fundamentada no Código de Ética do Profissional Psicólogo (Conselho Federal de Psicologia, 2005).

Dessa forma, ao pensar a formação em AP, é imperativo que se cuide de desenvolver as habilidades e competências básicas necessárias para uma boa prática. Neste sentido, é importante considerar a necessidade de disciplinas teóricas e práticas, além do estágio específico, a fim de que se possa, além de desenvolver a competência em realizar adequadamente uma AP, treinar as habilidades necessárias para uma boa condução de todo o processo.

Neste sentido, o ensino de AP em tempos de pandemia merece uma atenção especial, pois não se trata somente de extrapolar o ensino praticado 
presencialmente para o contexto remoto. Trata-se de assegurar o desenvolvimento das competências mínimas necessárias para o desenvolvimento adequado de um processo de avaliação psicológica, possibilitar o desenvolvimento e treino das habilidades necessárias para a boa prática e, por fim, garantir o sigilo e cuidado imprescindível dos testes psicológicos conforme preconizado no CEPP.

A Avaliação Psicológica é "um processo estruturado de investigação de fenômenos psicológicos, composto de métodos, técnicas e instrumentos, com o objetivo de prover informações à tomada de decisão, no âmbito individual, grupal ou institucional, com base em demandas, condições e finalidades específicas" (Conselho Federal de Psicologia, 2018a, Art. 1º). Dessa forma, pode-se dizer que a AP tem por finalidade responder a uma demanda inicial. Para isso, o psicólogo deve ter a competência necessária para avaliar qual o melhor método, técnica ou procedimento para avaliar a demanda que chegou, assim como ter a habilidade de utilizar diferentes métodos, técnicas e procedimentos a fim de responder adequadamente à demanda de uma pessoa, grupo ou instituição.

De acordo com a norma para AP atualmente vigente, a Resolução no 009/2018 (Conselho Federal de Psicologia, 2018a), esses meios de obtenção de dados são denominados "fontes fundamentais". As fontes fundamentais podem ser testes psicológicos, entrevistas psicológicas e anamnese, protocolos ou registros de observação, e o psicólogo deve, no processo de AP, fundamentar sua decisão em ao menos uma fonte fundamental. Contudo, a depender do contexto e demanda poderá complementar as informações por meio das fontes complementares. As fontes complementares são as técnicas e instrumentos não-psicológicos e documentos técnicos como relatórios de equipes multiprofissionais. Contudo, para que não incorra em falta ética é importante que o psicólogo saiba distinguir uma fonte complementar de um teste psicológico não avaliado ou ainda que saiba identificar a qualidade e base científica da fonte complementar utilizada. Essa capacidade reflexiva e analítica é de suma importância para o profissional psicólogo na prática de AP pois a ciência é dinâmica e cada vez mais interdisciplinar. Contudo, no exercício profissional da psicologia deve-se, sempre, estar atento ao papel da Psicologia no desenvolvimento da saúde e condições de vida dos indivíduos de forma ética e responsável e ancorado na ciência psicológica.
O ensino para a formação do psicólogo deve propiciar conhecimentos e atividades práticas para $\mathrm{o}$ desenvolvimento da competência para o uso das fontes fundamentais e capacidade de discernimento das fontes complementares. A parte prática do fazer psicológico dentro do ensino tende a ser aplicada durante os estágios ou laboratórios e associados a disciplinas ao longo do curso. Estes têm a função de propiciar aos alunos o exercício prático da AP de forma supervisionada. No entanto, no caso da AP, ao ser utilizada em disciplinas práticas e/ou estágios, demanda que o aluno já tenha desenvolvido competências mínimas (conhecimento teórico e habilidades) em relação ao uso de alguns métodos, técnicas e testes psicológicos. Neste sentido, é recomendável que o aluno já tenha tido contato e praticado a aplicação do teste psicológico antes de sua aplicação no contexto real. Isso porque no estágio ele realizará a AP, o processo de compreensão de um sujeito, grupo ou instituição para responder uma demanda e tomar uma decisão; mas, para isso, os meios a serem utilizados para a captura das informações a serem analisadas precisam já ser de conhecimento teórico e prático. Assim, no estágio se aperfeiçoa o uso das fontes fundamentais, mas não se inicia a prática delas, pois isso geraria graves problemas de coleta dos dados, inviabilizando o processo de AP e das intervenções a serem planejadas que devem ser embasadas nessa. Resumindo, o aluno não teria uma aprendizagem com qualidade do processo de AP e ainda poderia estar infringindo o CEPP na medida em que pode prejudicar o indivíduo que está participando do processo. Apesar do estágio ser uma etapa do ensino, de potencializar as competências e de permitir erros passíveis de correção, é uma prática que não pode prescindir do compromisso ético com o outro e com a sociedade que estão participando desse processo e contribuindo com a formação do aluno. No próprio CEPP (Conselho Federal de Psicologia, 2005), o Art. 17 discute sobre as condutas no ensino: "Caberá aos psicólogos docentes ou supervisores esclarecer, informar, orientar e exigir dos estudantes a observância dos princípios e normas contidas neste Código". Assim, as disciplinas anteriores ao estágio que tratam do ensino da AP devem englobar a parte teórica e a prática.

Dois estudos (Noronha, Castro, Ottati, Barros, \& Santana, 2013; Bardagi, Teixeira, Segabinazi, Schelini, \& Nascimento, 2015) tiveram como um de seus objetivos verificar metodologias utilizadas em disciplinas de AP por meio do relato de professores. 
No primeiro estudo participaram 22 professores e os resultados apontaram o uso de aulas expositivas (86,4\%); atividades práticas com aplicação de testes psicológicos, entrevistas, observações e realização de um processo de psicodiagnóstico $(78,7 \%)$; atividades em grupo, como seminários e estudos dirigidos (68,2\%); simulações de aplicação de testes entre os aluno e atividades similares $(45,5 \%)$; e elaboração de documentos (31,8\%) (Noronha et al, 2013). $\mathrm{O}$ segundo estudo contou com uma amostra de 47 professores que responderam a um questionário específico sobre as disciplinas de avaliação psicológica. Referente às estratégias de ensino em atividades práticas e de supervisão, constatou-se: correção e interpretação de testes psicológicos $(87,2 \%)$; apresentação de estudos de caso $(78,7 \%)$; aplicações dentro $(74,5 \%)$ e fora da sala de aula $(66,0 \%)$; prática de um processo de avaliação psicológica $(53,2 \%)$; observação de processos de avaliação $(31,9 \%)$; e outros tipos de atividades práticas (17\%) como simulação de aplicação de instrumentos e a observação em sala de espelho (8,5\%), discussão de estudos de caso $(6,4 \%)$, elaboração de documentos $(6,4 \%)$, construção de instrumentos $(2,1 \%)$ e levantamento de testes aprovados pelo Sistema de Avaliação dos Testes Psicológicos (SATEPSI) (2,1\%) (Bardagi et al, 2015).

Esses estudos demonstram a associação do uso de estratégias e metodologias de ensino que envolvem atividades práticas e de interação entre os alunos e entre os alunos e os professores com a utilização de outros espaços que não somente a sala de aula no ensino da AP. Neste sentido, cabe refletir sobre a necessidade e/ou importância do contexto físico (e não virtual) para o desenvolvimento de algumas das estratégias postuladas acima. A sala de aula física possibilita o desenvolvimento de muitas dinâmicas de ensino para trabalhar as habilidades dos alunos no uso e compreensão de métodos, técnicas e instrumentos e assim possibilitar um ambiente profícuo de desenvolvimento das competências mínimas para a realização de um processo de AP. Esse princípio da presencialidade para o ensino está em consonância com as DCNs, inclusive a de 2019, a qual foi elaborada compreendendo a importância, as facilidades e o papel das tecnologias de informação (TICs) e comunicação na vida da sociedade contemporânea. Assim, as DCNs (Conselho Nacional de Educação, 2019) instituem no Art. $3^{\circ}$ "O curso de graduação em Psicologia deve ser oferecido na modalidade presencial, tendo em vista a natureza complexa das competências profissionais do psicólogo, e segue os marcos legais para os cursos de bacharelado" (p. 6), mas por reconhecer a utilidade das TICs completa com o parágrafo único:

As ações de ensino a distância, mediadas pela tecnologia, direcionadas para os cursos de bacharelado, devem ser utilizadas com a finalidade de levar o estudante a compreender e utilizar as tecnologias digitais de forma crítica, reflexiva e ética, como recurso para acessar, disseminar e produzir conhecimento (p. 6).

Ou seja, no ensino, as TICs são ferramentas para que o aluno entre em contato com informações globalizadas, atualizadas, e para que possa compartilhar, sem barreiras sociais e econômicas, as suas produções, como por exemplo uma pesquisa científica. Porém, o ensino para o desenvolvimento das competências profissionais, como as necessárias para a realização da AP, devem ser essencialmente presenciais.

De acordo com o descrito nas DCNs sobre a complexidade das competências profissionais da psicologia, as relacionadas com a AP são exemplos típicos, pois como fazer uso com a qualidade técnica e ética de métodos, técnicas e instrumentos que pressupõem o contato presencial para se obter informações mais confiáveis? Como aplicar um teste psicológico sem ter a certeza de que quem responde é o avaliando e se o ambiente é sigiloso e seguro? Como realizar uma entrevista sem ter a observação minuciosa dos comportamentos não-verbais, se há outras pessoas constrangendo o avaliando? Esses e outros questionamentos permeiam a prática da AP por meio remoto/online, seja síncrono ou assíncrono, e devem ser refletidos antes do psicólogo oferecer o serviço nessa modalidade.

Essas reflexões também são válidas para o contexto de estágio em que são realizados os processos de AP. Embora supervisionado, trata-se de uma prática profissional e como tal deve resguardar todos os preceitos éticos da profissão. Assim, embora a Resolução CFP no 011/2018 (Conselho Federal de Psicologia, 2018b) regulamente a prestação de serviços psicológicos realizados por meios de tecnologias da informação e da comunicação e revogue a Resolução CFP no $11 / 2012$, ela não se sobrepõe ao CEPP. Neste sentido, é dever ético do psicólogo verificar se o serviço a ser oferecido cumprirá com o CEPP (Conselho Federal de Psicologia, 2005), o qual 
descreve como dever fundamental do psicólogo no Art. 1, alínea, "Prestar serviços psicológicos de qualidade, em condições de trabalho dignas e apropriadas à natureza desses serviços, utilizando princípios, conhecimentos e técnicas reconhecidamente fundamentados na ciência psicológica, na ética e na legislação profissional”.

Se tais questionamentos tendem a indicar que uma AP deveria ser realizada somente presencialmente, qual o motivo de desenvolver competências para a prática desse processo utilizando o ensino remoto/online síncrono ou assíncrono, que aumentam ainda mais os questionamentos? Como ensinar a aplicação de um instrumento sem a prática, sem que o aluno manipule concretamente os materiais, sem que treine os seus comportamentos para a aplicação, sem que o aluno observe os comportamentos não verbais do avaliando que são informações importantíssimas para uma análise qualitativa? Como o professor poderá observar e intervir para que o aluno saiba como aprimorar o seu comportamento para a aplicação? Como o aluno irá praticar antes de realizar uma aplicação do teste em um estágio, momento no qual já deveria ter desenvolvido minimamente a competência da aplicação?

As perguntas supramencionadas podem ser generalizadas para as demais técnicas, métodos e instrumentos. Por conta da natureza desses recursos de coleta de dados na AP é que os professores precisam utilizar metodologias e estratégias como as que foram descritas nos artigos de Noronha et al. (2013) e Bardagi et al. (2015). Em específico sobre os testes psicológicos, o ensino por meio remoto/online, ainda aumenta a divulgação destes a leigos, o que é uma infração ética conforme o CEPP (Conselho Federal de Psicologia, 2005) afirma em seu Art. 18: "O psicólogo não divulgará, ensinará, cederá, emprestará ou venderá a leigos instrumentos e técnicas psicológicas que permitam ou facilitem o exercício ilegal da profissão".

No entanto, mesmo mantendo o princípio da presencialidade para o ensino da AP em disciplinas teóricas, práticas e estágios, diante desse momento de profunda tristeza e mudanças causadas pela pandemia do Covid-19, orientações para o ensino da psicologia, especificamente para essa situação de consternação, foram elaboradas, incluindo para a AP. No geral, recomenda-se que sejam ensinadas de forma remota/online somente conteúdos teóricos. Sobre o ensino dos testes psicológicos, caso seja imprescindível, sugere-se o uso dos testes não-comercializados e disponibilizados por seus autores. Nesse sentido do cuidado ao fazer o uso dos testes no ensino, há demais orientações para esse momento de ensino remoto (Conselho Federal de Psicologia, 2020). Demais orientações também podem ser verificadas em Associação Brasileira de Ensino de Psicologia e Conselho Federal de Psicologia (2020), Marasca, Yates, Schneider, Feijó e Bandeira (2020), Schneider et al. (2020) e Zanini, Reppold e Faiad (2020).

\section{Referências}

Antunes, M. A. M. (2012). A Psicologia no Brasil: Um ensaio sobre suas contradições [Número especial]. Psicologia: Ciência e Profissão, 32, 44-65. https://doi.org/10.1590/S1414-98932012000500005

Associação Brasileira de Ensino de Psicologia, Conselho Federal de Psicologia, \& Federação Nacional dos Psicólogos. (2020). Nota sobre atividades acadêmicas nos cursos de graduação em Psicologia em tempos de pandemia. https://site.cfp.org.br/wp-content/uploads/2020/03/Nota-sobre-atividades-acad\%C3\%AAmicas-nos-cursosde-gradua\%C3\%A7\%C3\%A3o-em-Psicologia-em-tempos-de-pandemia-Atualizada-1.pdf

Associação Brasileira de Ensino de Psicologia \& Conselho Federal de Psicologia. (2020). Realização de estágios e práticas nos cursos de graduação em Psicologia no contexto da pandemia de COVID-19: Posição e orientaçães do CFP e ABEP.https://drive.google.com/file/d/1_Ij9-EzNl4dUiRTk1VSV030hjQliEorR/view

Bardagi, M. P., Teixeira, M. A. P., Segabinazi, J. D., Schelini, P. W., \& Nascimento, E. (2015). Ensino de avaliação psicológica no Brasil: Levantamento com docentes de diferentes regiões. Avaliação Psicológica, 14(2), 253-260.

Boarini, M. L. (2007). A formação do psicólogo. Psicologia em Estudo, 12(2), 443-444. https://doi.org/10.1590/ S1413-73722007000200027

Bock, A. M. B. (org.). (2003). Psicologia e o compromisso social. Cortez.

Brasil. (2008). Lei $N^{\circ} 11.788$, de 25 de setembro de 2008. Dispõe sobre o estágio de estudantes; altera a redação do art. 428 da Consolidação das Leis do Trabalho - CLT, aprovada pelo Decreto-Lei $\mathrm{n}^{\circ} 5.452$, de $1^{\circ}$ de maio de 1943, e a Lei $\mathrm{n}^{\circ}$ 9.394, de 20 de dezembro de 1996; revoga as Leis $\mathrm{n}^{\text {os }}$ 6.494, de 7 de dezembro de 1977, e 8.859, de 23 de março 
de 1994, o parágrafo único do art. 82 da Lei no 9.394, de 20 de dezembro de 1996, e o art. $6^{\circ}$ da Medida Provisória nº 2.164-41, de 24 de agosto de 2001; e dá outras providências. Presidência da República.

Brzezinski, I. (2010). Tramitação e desdobramentos da LDB/ 1996: Embates entre projetos antagônicos de sociedade e de educação. Trabalho, Educação, Saúde, 8(2), 185-206. https://doi.org/10.1590/S1981-77462010000200002

Campos, H. R., Souza, M. P. R, \& Facci, M. G. D. (Orgs.) (2018). Psicologia e Políticas Educacionais (2a ed.). Appris.

Campos, K. C. L., Duarte, C., Cezar, E. O., \& Pereira, G. O. A. (2011). Psicologia organizacional e do trabalho: Retrato da produção científica na última década. Psicologia: Ciência e Profissão, 31(4), 702-717. https://doi.org/10.1590/ S1414-98932011000400004

Castro, G. J. M., \& Costa, M. L. (2018). A invenção do sujeito. Psicologia: Ciência e Profissão, 38(2), 391-402. https:// doi.org/10.1590/1982-3703003012017.

Chaui, M. e Nogueira, M. A. (2007). O pensamento político e a redemocratização do Brasil. Lua Nova, (71), 173-228. https:// doi.org/10.1590/S0102-64452007000200006

Cintra, M. S., \& Bernardo, M. H. (2017). Atuação do psicólogo na atenção básica do SUS e a Psicologia Social. Psicologia: Ciência e Profissão, 37(4), 883-896. https://doi.org/10.1590/1982-3703000832017

Conselho Federal de Psicologia. (2003). Resolução CFP $n^{\circ}$ 007/2003. https://site.cfp.org.br/wp-content/uploads/ 2003/06/resolucao2003_7.pdf

Conselho Federal de Psicologia. (2005). Código de Ética Profissional do Psicólogo. http://site.cfp.org.br/wp-content/ uploads/2012/07/codigo_etica.pdf

Conselho Federal de Psicologia. (2007). Resolução CFP $n^{\circ}$ 003/2007. https://site.cfp.org.br/wp-content/uploads/ 2007/02/resolucao2007_3.pdf

Conselho Federal de Psicologia. (2009). Resolução CFP no 001/2009. https://site.cfp.org.br/wp-content/uploads/ 2009/04/resolucao2009_01.pdf

Conselho Federal de Psicologia. (2013). Carta de serviços sobre estágios e serviços-escola. http://site.cfp.org.br/ publicacao/carta-de-servicos-sobre-estagios-e-servicos-escola/

Conselho Federal de Psicologia. (2018a). Resolução nº 009, de 25 de abril de 2018. https:/ /site.cfp.org.br/wp-content/ uploads/2018/04/Resolução-CFP-no-09-2018-com-anexo.pdf

ConselhoFederal dePsicologia. (2018b). Resolução CFPn $n^{\circ}$ 11/2018.https:/ /e-psi.cfp.org.br/resolucao-cfp-no-11-2018/

Conselho Federal de Psicologia. (2019). Resolução CFP no 18, de 05 de setembro de 2019. https:/ / bit.ly/2UHpXXR

Conselho FederaldePsicologia. (2020). Cartilhadeboaspráticasparaavaliaçãopsicológicaem contextosdepandemia. https://site.cfp.org.br/wp-content/uploads/2020/08/clique-aqui.pdf

Conselho Federal de Psicologia \& Associação Brasileira de Ensino de Psicologia. (2018). Ano da Formação em Psicologia. https://site.cfp.org.br/wp-content/uploads/2018/07/RELAT\%C3\%93RIO-FINAL-REVIS\%C3\%83ODAS-DIRETRIZES-CURRICULARES-NACIONAIS-PARA-OS-CURSOS-DE-GRADUA\%C3\% 87\%C $3 \%$ 83O-EM-PSICOLOGIA.pdf

Conselho Federal de Psicologia \& Associação Brasileira de Ensino de Psicologia. (2020). Práticas e estágios remotos em Psicologia no contexto da pandemia da Covid-19: Recomendações. https://site.cfp.org.br/wp-content/ uploads /2020/08/Caderno-de-orientac\%CC\%A7o\%CC\%83es-formac\%CC\%A7a\%CC\%83o-e-esta\%CC\% 81gios_FINAL2_com_ISBN_FC.pdf

Conselho Nacional deEducação. (2004). Resoluçãono ${ }^{\circ}$, de 7 demaio de2004. http://portal.mec.gov.br/cne/arquivos/ pdf/rces08_04.pdf

Conselho Nacional de Educação. (2011). Resolução no5, de 15 de março de 2011.http:/ / portal.mec.gov.br/index.php? option=com_docman \&view=download \&alias=7692-rces005-11-pdf \&Itemid=30192

Conselho Nacional de Educação. (2019). Parecer CNE/CES no 1071/2019. http://portal.mec.gov.br/index.php?option=com_docman\&view=download\&alias=139201-pces1071-19\&category_slug=dezembro-2019-pdf \&Itemid=30192

Conselho Nacional de Educação (2020). Parecer CNE/CP $n^{\circ}$ 5/2020. http://portal.mec.gov.br/index.php?option=com_docman\&view=download \&alias=145011-pcp005-20\&category_slug=marco-2020-pdf\&Itemid=30192

Cortez, P. A. (2019). Manual de desenvolvimento de instrumentos psicológicos: Contribuições emergentes em psicometria e avaliação psicológica. Revista Avaliação Psicológica, 18(1), 108-110. https://www.researchgate.net/ deref/http\%3A\%2F\%2Fdx.doi.org\%2F10.15689\%2Fap.2019.1801.15431.12 
Cury, B. M., \& Neto, J. L. F. (2014). Do currículo mínimo às diretrizes curriculares: Os estágios na formação do psicólogo. Psicologia em Revista, 20(3), 494-512. http://dx.doi.org/DOI-10.5752/P.1678-9523.2014V20N3P494

Grupo de Pesquisa Trabalho, Precarização e Resistências \& Centro de Estudos e Pesquisas em Humanidades da Universidade Federal da Bahia. (2019). Dossiê sobre o Programa Future-se do governo/MEC e as implicações para a universidade e a sociedade. https://gtfuturese.paginas.ufsc.br/files/2019/08/Dossie\%CC\%82-FUTURE-SE-ufba.pdf

Freud, S. (1987). Sobre a psicopatologia da vida cotidiana. Imago.

Gil, A. C. (1985). O psicólogo e sua ideologia. Psicologia: Ciência e Profissão, 5(1), 12-17. https://doi.org/10.1590/ S1414-98931985000100005

Ghiraldello, A.V. (2005). Neoliberalismo: Da crítica à crítica radical. In S. C. Urt, \& M. T. Morettini (Orgs.), A Psicologia e os desafios da prática educativa. UFMS.

International Association of Applied Psychology \& International Union of Psychological Science. (2016). International Declaration on Core Competences in Professional Psychology. https://www.iupsys.net/dotAsset/ 1fd6486e-b3d5-4185-97d0-71f512c42c8f.pdf

Jacó-Vilela, A. M. (1999). Formação do psicólogo: Um pouco de história. Interações: Estudos e Pesquisas em Psicologia, 8(4), 79-91.

Júnior, J. R. S., \& Fargoni, E. H. E. (2020). Globalización financiera, dependencia y cambios institucionales: Notas económicas y políticas sobre las reformas en el Brasil actual. Revista Internacional de Educação Superior, 7, 1-11. https://doi.org/10.20396/riesup.v7i0.8660381

Kahhale, E. M. P. (org.) (2018). A diversidade da Psicologia: Uma construção teórica. Cortez.

Matz, S. C., Kosinski, M., Nave, G., \& Stillwell, D. J. (2017). Psychological targeting as an effective approach to digital mass persuasion. Proceedings of the National Academy of Sciences, 114(48), 12714-12719. https://doi.org/10.1073/ pnas. 1710966114

Marasca, A. R., Yates, D. B., Schneider, A. M.A., Feijó, L. P., \& Bandeira, D. R. (2020). Avaliação psicológica online: considerações a partir da pandemia do novo coronavírus (Covid-19) para a prática e o ensino no contexto a distância. Estudos de Psicologia (Campinas), 37, e200085. Epub June 05, 2020. https://dx.doi.org/10.1590/1982-0275202037e200085

Ministério da Educação (2020a). Portaria no 343, de 17 de março de 2020. Dispõe sobre a substituição das aulas presenciais por aulas em meios digitais enquanto durar a situação de pandemia do Novo Coronavírus - Covid-19. Presidência da República.

Ministério da Educação (2020b). Portaria no 544, de 16 de junho de 2020. Dispõe sobre a substituição das aulas presenciais por aulas em meios digitais enquanto durar a situação de pandemia do novo coronavírus - Covid-19, e revoga as Portarias MEC no 343, de 17 de março de 2020, no 345, de 19 de março de 2020, e no 473, de 12 de maio de 2020. Presidência da República.

Moscovici, S. (2003). Representações sociais: Investigações em Psicologia Social. Vozes.

Noronha, A. P. P., Castro, N. R., Ottati, F., Barros, M. V. C., \& Santana, P. R. (2013). Conteúdos e metodologias de ensino de avaliação psicológica: Um estudo com professores. Paidéia (Ribeirão Preto), 23(54), 129-139. https://doi.org/10.1590/1982-43272354201315

Nunes M. F. O., Muniz, M., Reppold, C. T., Faiad, C., Bueno, J. M. H., \& Noronha, A. P. P. (2012). Diretrizes para o ensino de avaliação psicológica. Avaliação Psicológica, 11(2), 309-316. http://pepsic.bvsalud.org/ scielo.php?script=sci_arttext \&pid=S1677-04712012000200016 \&lng=pt.

Patto, M. H. S. (1984). Psicologia e ideologia. TA Queiroz.

Pereira,E. M.A. (2014). A construção do conhecimento na modernidade ena pós-modernidade:Implicações para auniversidade. Ensino Superior Unicamp, 5(14), 13-24. http://repositorio.unicamp.br/jspui/handle/REPOSIP/119465

Piaget, J. (1974). O nascimento da inteligência na criança. Zahar.

Prates, B. V., Feitosa, E. A. L., Monteiro, P. S., \& Branco, P. C. C. (2019). Considerações sobre a formação do psicólogo no Brasil: Revisão sistemática. Estudos Interdisciplinares em Psicologia, 10(2), 97-115. http://dx.doi.org/ 10.5433/2236-6407.2019v10n2p97

Primi, R. (2018). Avaliação psicológica no século XXI: De onde viemos e para onde vamos [Número especial]. Psicologia: Ciência e Profissão, 38, 87-97. https:// doi.org/10.1590/1982-3703000209814 
Rechtman, R. (2015). O futuro da Psicologia brasileira: Uma questão de projeto político. Psicologia, Diversidade e Saúde, 4(1), 69-77. http://dx.doi.org/10.17267/2317-3394rpds.v4i1.578

Schneider, A. M. A., Marasca, A. R., Yates, D. B., Feijó, L. P., Rovinski, S. L. R., \& Bandeira, D. R. (2020). Boas práticas para a avaliação psicológica online. GEAPAP. http://www.ufrgs.br/geapap/arquivos/E-book-GEAPAP-BoasPraticas-Versao-5.pdf

Schultz, D. P., \& Schultz, S. E. (2005). História da Psicologia Moderna (S. S. M. Cuccion, Trad.). Pioneira Thomson Learning.

Seixas, P. S. (2014). A formação graduada em Psicologia no Brasil: Uma reflexão sobre os principais dilemas em um contexto pós-DCN [Tese de doutorado, Universidade Federal do Rio Grande do Norte]. Repositório Institucional UFRN. https://repositorio.ufrn.br/jspui/handle/123456789/17401

Soligo, A. (2010). Psicologia no ensino médio: Reflexões em torno da formação. In Conselho Regional de Psicologia do Estado de São Paulo, Ensino de Psicologia no nível médio: impasses e alternativas. CFP.

Sousa, A. H. (2019). Mercantilização e automação do ensino superior privado: O caso da educação a distância. Fepesp. http://fepesp.org.br/artigo/7078

Urt, S. (org.) (2017). Retratos do pesquisar em MS: Educação e Psicologia. Oeste.

Vilela, A. M. J. (2012). História da Psicologia no Brasil: Uma narrativa por meio de seu ensino [Número especial]. Psicologia: Ciência e Profissão, 32, 28-43. https://doi.org/10.1590/S1414-98932012000500004

Zanini, D. S., Reppold, C. T., \& Faiad, C. (2020). Do lápis e papel à modalidade remota: Considerações sobre a avaliação psicológica em tempos de pandemia. In K. Oliveira, M. Muniz, D. S. Zanini, T. H. Lima, \& A. A. A. Santos (Orgs.), Formação e estratégias de ensino em Avaliação Psicológica [Manuscrito em preparação]. Vozes.

\section{Angela Fátima Soligo}

Doutora em Psicologia pela Pontifícia Universidade Católica de Campinas; docente colaboradora da pós-graduação em Educação da Universidade Estadual de Campinas, Campinas - SP, Brasil.

E-mail: angelasoligo@gmail.com

(1) https://orcid.org/0000-0001-7056-6649

\section{Irani Tomiatto de Oliveira}

Doutora em Psicologia Clínica pelo Instituto de Psicologia da Universidade de São Paulo (USP), São Paulo - SP. Brasil.

E-mail: iranitomiatto@gmail.com

(1) https://orcid.org/0000-0002-6205-179X

\section{Monalisa Muniz}

Docente do Programa de Pós-Graduação em Psicologia do Departamento de Psicologia da Universidade Federal de São Carlos, São Carlos - SP. Brasil.

E-mail:monamuniz@gmail.com

(1) https://orcid.org/0000-0003-1628-6296

\section{Daniela Sacramento Zanini}

Docente do Programa de Pós-Graduação em Psicologia da Pontifícia Universidade Católica de Goiás, Goiânia - GO. Brasil.

E-mail: dazanini@yahoo.com

(1) https:// orcid.org/0000-0003-2515-2820

Endereço para envio de correspondência:

Universidade Estadual de Campinas, Faculdade de Educação. Rua Bertrand Russel, 801, Cidade Universitária Zeferino Vaz. CEP: 13083-970. Campinas - SP. Brasil. 
Psicologia: Ciência e Profissão 2020 v. 40, e243432, 1-18.

Recebido 30/09/2020

Aceito 30/09/2020

Received 09/30/2020

Approved 09/30/2020

Recibido $30 / 09 / 2020$

Aceptado 30/09/2020

Como citar: Soligo, A. F, Oliveira, I. T., Muniz, M., \& Zanini, D. S. (2020). Formação em Psicologia: Estágios e Avaliação Psicológica. Psicologia: Ciência e Profissão, 40, 1-18. https://doi.org/10.1590/1982-3703003243432

How to cite: Soligo, A. F., Oliveira, I. T., Muniz, M., \& Zanini, D. S. (2020). Psychology Training: Internships and Psychological Assessment. Psicologia: Ciência e Profissão, 40, 1-18. https://doi.org/10.1590/1982-3703003243432

Cómo citar: Soligo, A. F., Oliveira, I. T., Muniz, M., \& Zanini, D. S. (2020). Formación en Psicología: Pasantías y Evaluación Psicológica. Psicologia: Ciência e Profissão, 40, 1-18. https://doi.org/10.1590/1982-3703003243432 